\title{
Anatomical and technical bases of digestive surgery
}

Bases anatômicas e técnicas da cirurgia digestiva

Aldo da Cunha Medeiros, Ítalo Medeiros Azevedo

Study performed at Department of Surgery, Federal University of Rio Grande do Norte (UFRN), Brazil.

Financial support: none.

Conflict of interest: None.

Correspondence address: Department of Surgery, Federal University of Rio Grande do Norte, at Ave. Nilo

Peçanha 620, Natal, RN, Brazil, E-mail: cirurgex.ufrn@gmail.com

Submitted: May 20, 2016. Accepted, after review: June 21, 2016.

\begin{abstract}
Purpose: To discuss relevant issues concerned to surgical anatomy of digestive tract organs and their influence on surgical technique and operative tactics. Methods: The literature for this review was collected with PubMed and SciElo search using the combination of digestive tract, esophagus, stomach, small bowel, colon, surgical anatomy, operative technique, and the specific terms for anatomy. Results: This review has permited to stablish and emphasize the most relevant details of surgical anatomy of digestive tract associated to the facilities and technical difficulties encountered by surgeons when operating esophagus, stomach and intestines. Conclusion: Surgical anatomy of digestive tract is rich in essential details for surgery of the organs involved in this area, assisting surgeons about technical facilities and difficulties encountered in the operating room.
\end{abstract}

Key words: Gastrointestinal tract. Esophagus. Stomach. Small bowel. Colon. Surgical anatomy. Anastomosis.

\section{RESUMO}

Objetivo: Discutir a anatomia cirúrgica dos órgãos do aparelho digestivo e sua influência na técnica e táticas operatórias. Métodos: A literatura para esta revisão foi coletada em pesquisa nas bases de dados PubMed e SciELO, usando a combinação das palavras chave aparelho digestivo, esôfago, estômago, intestino delgado, cólon, anatomia cirúrgica e técnica operatória. Resultados: Esta revisão permitiu estabelecer e enfatizar os detalhes mais relevantes da anatomia cirúrgica do aparelho digestivo associado às facilidades e dificuldades técnicas encontradas pelos cirurgiões durante as operações do esôfago, estômago e intestinos. Conclusão: A anatomia cirúrgica do aparelho digestivo é rica em detalhes essenciais para a cirurgia dos órgãos envolvidos nesta área, auxiliando cirurgiões quanto a facilidades e dificuldades técnicas vivenciadas na sala de cirurgia. 
Descritores: Aparelho digestivo. Esôfago. Estômago. Intestino delgado. Cólon. Anatomia. Cirurgia.

\section{INTRODUCTION}

Sutures and anastomoses in digestive tract are the most common procedures performed by general surgeons and surgeons of the alimentary tract. In this report we discussed relevant issues concerned to surgical anatomy of digestive tract organs. Surgical anatomy, surgical technique and tactics are described, emphasizing the facilities and technical difficulties encountered by surgeons when operating esophagus, stomach, small bowel and colon.

\section{SURGICAL ANATOMY OF ESOPHAGUS}

The esophagus is a predominantly muscular tube that begins as the continuation of the pharynx in the neck and ends at the junction with the stomach. The esophagus descends anteriorly to the vertebral column through the middle mediastinum and traverses the diaphragmatic hiatus into the abdomen at the level of the tenth thoracic vertebral body. After entering the abdomen it joins the stomach along the lesser curvature at what is called the cardia. The length of the entire esophagus ranges from 19 to $25 \mathrm{~cm}$ (median $22 \mathrm{~cm}$ ) in men, and 18 to 22 $\mathrm{cm}$ (median $21 \mathrm{~cm}$ ) in women. Topographically, the esophagus is divided into 3 regions: cervical, thoracic, and abdominal. The cervical esophagus is bordered anteriorly by the trachea, posteriorly by the vertebral column and the prevertebral fascia, and laterally on each side by the carotid sheaths and the thyroid gland. These are important anatomical relations for the surgeon. The thoracic esophagus is approximately $20 \mathrm{~cm}$ long and extends from the thoracic inlet to the diaphragmatic hiatus. From the thoracic inlet to the tracheal bifurcation the thoracic esophagus is related anteriorly to the membranous wall of the trachea and posteriorly to the prevertebral fascia and spine. The esophagus descends posterior to the aortic arch and then lies to the right of the descending thoracic aorta, and posterior and to the right of the subcarinal lymph nodes and the pericardium. The right lateral surface of the thoracic esophagus is covered by parietal pleura. The left lateral surface of the thoracic esophagus is covered 
proximally by the left subclavian artery and the parietal pleura. Distally the left lateral surface of the esophagus is covered by the descending thoracic aorta until the level of the eighth thoracic vertebra and subsequently only by the parietal pleura. Posteriorly, the thoracic esophagus remains in contact with the vertebral bodies and follows the spine until the level of the eighth thoracic vertebra. At this level the esophagus moves anterior to the aorta and enters through the esophageal hiatus into the abdomen. The abdominal portion of the esophagus begins once the esophagus transits the diaphragmatic hiatus and ends when it joins the cardia of the stomach along the high lesser curvature. The intraabdominal length of the esophagus is typically 2 to $6 \mathrm{~cm}$ long ${ }^{1}$.

The cervical esophagus is predominantly irrigated by branches from the inferior thyroid artery, also receiving branches of the vertebral and subclavian arteries. Keeps important anatomical relations with the trachea, carotid, internal jugular, thyroid, recurrent nerve, but the cervical surgical approach is easy compared to the other segments. The thoracic segment is the largest. It is deeply located in the medium and posterior mediastinum, mainly irrigated by small arteries, branches of the aorta, the bronchial artery and intercostals arteries. This can be considered a deficient vascularisation when compared to the stomach. His anatomical relationships occur with the spine, trachea, bronchi, pericardium, great vessels of the heart, vagus nerve and diaphragmatic hiatus. The thoracic esophagus can be considered of difficult surgical access. The abdominal segment communicates with the stomach and gets up branch irrigation from the left gastric artery and left subdiafragmatic artery.

The esophageal wall structure differs from the stomach and intestines, for three main aspects: esophagus is not protected by serosa; its muscles are predominantly longitudinal; the proximal longitudinal muscle layer, which is located above the aortic arch consists of striated fibers. Below the aortic arch, the muscle fibers are smooth and offer less support for sutures than striated fibers. Closer to the esophago-gastric junction, the worse the quality of the esophageal muscles to practice anastomoses. The esophagus has thick mucosa, composed of stratified squamous epithelium. The anatomical characteristics of the esophagus offer several technical difficulties for surgery, especially in their approach and anastomoses. They are: difficult access, the esophagus is not 
covered by serosa, that implies low support and protection for the sutures, as well the predominantly arrangement of muscles hinder rapprochement ends after resection and anastomoses without tension. Surgeons prefer to perform anastomoses with stapler; they are easier to perform in esophagus, compared with hand sewn anastomoses ${ }^{2}$. For all the anatomical and technical problems that the esophagus provides for sutures and anastomoses, the incidence of postoperative fistula, and morbidity is high ${ }^{3-5}$.

\section{Surgical anatomy versus technical problems in the esophagus surgery}

Deep situation in mediastinum; difficult access; Lack of supporting tissue; serous absence; insufficient segmentar vascularization; largest contingent of longitudinal muscle fibers; restricted extensibility; proximity to vital organs; high septic content (continuity with oropharynx); high incidence of fistulas and dehiscence 6 .

\section{SURGICAL ANATOMY OF STOMACH}

The stomach extends from the esophagus to the duodenum. It lies in the upper left quadrant of the abdomen behind the lower ribs and anterior abdominal wall and is separated from the left lung and pleura by the dome of the diaphragm. The stomach is covered by peritoneum on each surface. These meet at the curvatures to form the lesser omentum above and the greater omentum below.

Relations are important for surgeons: Anterior: liver to the right, diaphragm to the left; anterior- abdominal wall. Posterior: body of pancreas, part of left kidney, and left suprarenal, splenic artery and spleen. These form the 'bed' of the stomach. The transverse mesocolon passes from the lower border of the pancreas to the transverse colon.

\section{Arterial blood supply}

The stomach is richly vascularized, with contributions from five major sources: (1) the left gastric artery, a branch of the celiac axis, which supplies the cephalad portion of the lesser curvature; (2) the right gastric artery, a branch of 
the common hepatic artery, which supplies the caudal portion of the lesser curvature; (3) the right gastroepiploic artery, a branch of the gastroduodenal artery, which supplies the antrum and lower corpus; (4) the left gastroepiploic artery, a branch of the splenic artery, which supplies the upper corpus; and (5) a series of short gastric arteries passing to the fundus and cephalad portion of the corpus from the splenic hilum, and thus ultimately from the splenic artery. An inconstant branch to the pylorus has been also described, often as a branch of the gastroduodenal artery. On the lesser curvature, the left gastric artery does not always trace directly back from the lesser curvature to the celiac axis; in some cases it dips behind the body the pancreas before ascending posteriorly. On the greater curvature, there is a small bare area between the entrances of the right and left gastroepiploic into the gastric wall. This bare area serves as a useful landmark in identifying the proximal extent of the gastric antrum, corresponding to the incisura on the lesser curvature?.

The stomach has an extensive submucosal arterial and venous network. This submucosal plexus allows the surgeon to make the ligature of 3 of the 4 major arteries of the stomach, and a single artery can supply the entire organ with low risk of ischemia. This anatomical detail facilitates resections and gastric anastomoses, with minimal risk of ischemia in anastomoses zones.

\section{Technical facilities for surgery versus stomach anatomy}

The most performed surgeries in the stomach are the Billroth I and Billroth II gastrectomies ${ }^{8}$. From a surgical point of view, the stomach is technically very favorable for the surgeon: the surgical approach (Access) is easy, except cardia; It is completely covered by the peritoneum; It has excellent vascularization; the wall has good structure, with 3 muscle layers that intersect; and the content is almost aseptic due to the low mucosa $\mathrm{pH}$.

\section{SURGICAL ANATOMY OF SMALL BOWEL}

The duodenum is the first portion of the small intestine. Beginning at the duodenal cap beyond the pylorus, it extends about 30 to $30 \mathrm{~cm}$ to the ligament of Treitz, the anatomic point where the jejunum deigns. The organ is divided into 
four points: the bulb, followed by the second (descending), trird (transverse, ans fourth (ascending) portions.

The duodenum is a predominantly fixed and retroperitoneal organ, and is not covered by peritoneum. It has anatomical relationships with the head of the pancreas, common bile duct, portal and superior mesenteric veins. The second and third points of duodenum are difficult to access for surgery. It has good vasculature, all of it derived from pancreatoduodenal arteries ${ }^{9}$. Starting from the fact that the duodenal mucosa is permanently bathed in hydrochloric acid, bile and pancreatic juices, and that it has no peritoneum protection, sutures and anastomoses in the duodenum may be considered high risk of fistulas and dehiscence and require special technical care ${ }^{10}$.

As jejunum runs into ileum the features change. Although both have large surface areas internally to aid absorption, the circular folds of mucous membrane decrease in number and size in the ileum and are almost completely absent in the lower ileum so the wall feels thinner. Throughout the small intestine aggregations of lymph follicles are present. These are more marked in the ileum and are called Peyer's patches. They occur on the anti-mesenteric border. Another difference is that mesenteric fat is less abundant near the intestinal wall in the jejunum so that the vessels to the gut can be seen with mesenteric transparent windows between them.

\section{Blood supply of small bowel:}

The arterial supply: the superior mesenteric artery crosses the third part of the duodenum to enter the root of the mesentery and pass downward towards the right iliac fossa. It gives off several jejunal and ileal arteries, which divide and reunite to supply the small bowel. In doing so, they form a series of arterial arches and arcades. so one or more of the main trunks may be ligated without affecting the blood supply.

The venous drainage: the veins drain the gut along the arterial pathways and empty into the superior mesenteric vein which joins the portal vein on its way to the liver. 


\section{Practical points for the surgeons:}

1- The duodenojejunal flexure is a site which must always be carefully examined in patients with deceleration injuries because disruption can occur.

2- The fact that the blood supply of the small bowel is organised in arches and arcade allows to ligate one of the main trunks without affecting the blood supply. This is done when constructing an ileal pouch for anastomosis to the rectum, or in distal esophagectomy with small bowel interposition.

adenomatous polyposis

3- The jejunum- ileum is completely covered by serosa, is easily accessible along its entire length and receives vascularization of the superior mesenteric artery. Unlike the stomach, the small intestine has no large submucosa plexus. So that the short vessels, by penetrating the gut wall, establish very few anastomoses with neighbors or these anastomoses are very poor. The same applies to the vasculature of the colon ${ }^{11}$.

Therefore, surgeons must pay special attention during bowel resections with the ligatures of vessels in the vicinity of resection areas and their anastomotic suture zones to prevent ischemia, fistulas and dehiscence. This anatomical detail of great importance for enterectomy and anastomoses is illustrated in Figure 1.

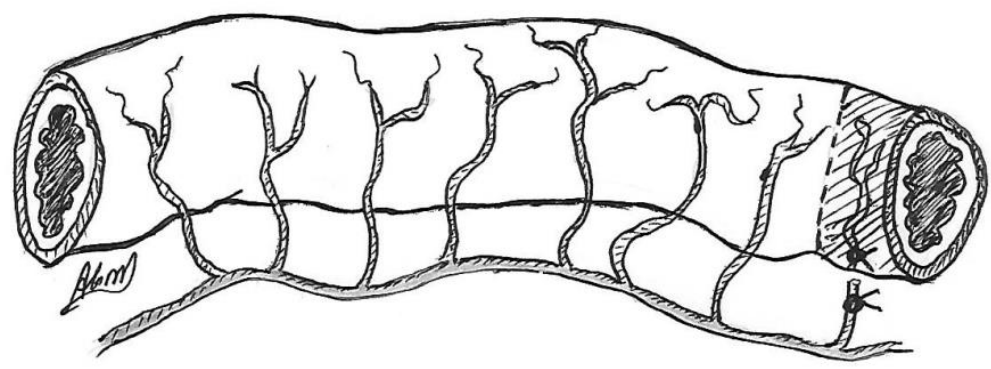

Figure 1. Details of the intestinal vasculature are observed. Short vessels penetrate perpendicularly to the bowel wall and do scarce or no intraparietal anastomoses with neighboring vessels. Inadvertent ligation of a blood vessel that supplies the anastomosis area (shaded) can compromise it and cause dehiscence or fistula. 


\section{Surgical anatomy versus technical difficulties and facilities for bowel surgery}

In short, the small bowel has an easy surgical access, except the duodenum; It is well vascularized; has poor vascular anastomoses in the bowel wall; It is covered by peritoneum, except the duodenum; and has increasing lumen septic content from the duodenum to the ileum.

\section{SURGICAL ANATOMY OF COLON}

The colon consists of appentix, cecum, ascending colon, transverse colon, descending colon, sigmoid, rectum and anal canal. The right colon is composed of cecum, ascending colon the hepatic flexure, and proximal transverse colon. The left colon is comprised of the distal transverse colon, the splenic flexure, the descending colon, the sigmoid and the rectosigmoid colon. The lumen is wide in the caecum and ascending colon but gradually narrows towards the sigmoid colon.

Colon Structure:It has a peritoneal coat complete over the caecum, appendix, transverse colon and sigmoid colon but incomplete elsewhere. There are small pouches of peritoneum filled with fat over all of the colon-appendices epiploicae.

The outer muscular coat is disposed in three longitudinal bands-the taenia coli. These converge upon the root of the appendix proximally. At the other end they become continuous with the longitudinal layer of the rectum. They are shorter than the colon so its wall becomes puckered into sacculations-colonic haustrations.

The colon has several features in its various portions. The ascending and descending colon are fixed to the posterior wall of the abdominal cavity and therefore peritoneum is coated only on its front side. The transverse and sigmoid colons are mobile and easier to access, fully covered by peritoneum. 


\section{The blood supply of colon is done as follows}

The cecum and appendix: from the superior mesenteric and ileocolic arteries; Ascending colon: from ileocolic and right colic arteries; Transverse colon/flexures: from the right middle and left colic arteries; Descending colon: left colic artery, and sigmoid and upper rectum by left colic, superior rectal arteries.

The lymphatic drainage is done along the arterial supply. Nodes are situated on the bowel surface, between the layers of the mesocolon, along the branches of the mesenteric arteries and along the trunks of the main vessels.

Nowadays, the radiologic anatomy by using computed tomography and magnetic ressonance imaging makes possible to correlate three-dimensional images with anatomy ${ }^{12-14}$.

Vascularization is derived from the superior and inferior mesenteric arteries, forming an extensive continuous arch bordering the entire length of the colon. Because of this arcade, colon segments can be used for the replacement of remote organs (ex.: esophagus) and may be sutured to the cervical esophagus without compromise its vascularization.

\section{Surgical anatomy versus technical difficulties and facilities for colon surgery}

The surgical access is easy, specially to the transverse and sigmoid colons; Hepatic and splenic angles are difficult to access; only the transverse and sigmoid are fully covered by peritoneum; weak muscles, except in taenia coli; colon is well vascularized; poor intraparietal vascular anastomoses; vascular arcades facilitate the use of the colon to replace other organs such as the esophagus after esophagectomy; Colon has very high septic content.

\section{DIGESTIVE ANASTOMOSiS}

Digestive anastomosis are widely practiced procedures for general surgery, which serve to communicate organs of the digestive tract. They are used both to reconstruct the food transit after resections, to divert traffic (bypass), and 
to evacuate secretions or fluid collections. They are called by stomia suffix plus the prefix that identifies the digestive organs involved in intercommunication.

They can be performed:

- With small bowel straps together, for example after enterectomy

- With jejunal loop with the stomach, as in subtotal gastrectomy (gastrojejunostomy)

-With ileum loop and colon as in the right colectomies

- Between colon loops, as in the transverse colectomy.

- Between intestinal loop and bile ducts, as in choledocoduodenostomies.

- Between intestinal loop and cavities containing fluid collections (pancreatic pseudocyst, for example), as in pseudocistojejunostomy.

- Etc

Surgical procedures practiced in the esophagus, stomach and intestines are characterized by a first septic phase, when the surgeon performs the opening of the viscera. Obligatorily should be avoided stroke gastroenteric contents into the abdominal cavity. The handling of the viscera must be careful and gentle, avoiding abrupt maneuvers, and eviscerations because the trauma and the massive output of the viscera of the abdominal cavity can result in dehydration and hypotensive reflex, one of the causes of hypotension and shock during surgery ${ }^{15}$.

\section{TYPES OF DIGESTIVE ANASTOMOSES}

The disposition of anastomotic mouths: Temino-terminal (end-to-end); end-to-side; latero-lateral (side-to-side).

\section{As for suturing layers:}

In one extra-mucous layer; In one-layer including mucosa In two-layers 
The end-to-end anastomosis is the most widely used, simpler, easier and faster execution. The calibers of the anastomotic ends may be different. To circumvent this technical detail, the surgeon may use the artifice of a longitudinal incision in the antimesenteric border of the narrow end, so the end opening widens enough to be equivalent to further opening of the other anastomotic. One of eventualities in which this occurs is in the ileum-colic right colectomy anastomosis. The end-to-side anastomosis is used very often in making the $Y$ Roux and the ileocolostomies, where the axes of the loops involved are sutures in a perpendicular direction.

As for side-to-side anastomosis, the more frequent use occurs in bypass of the digestive tract, as occurs in palliative operations. The arrangement of anastomosing loops occurs in parallel. It has the advantage of being able to make the anastomotic stoma of desired size, according to the case. Anastomosis may be performed by manual-machanical technique or by stapler ${ }^{16-18}$.

\section{SINGLE-LAYER VERSUS TWO-LAYER ANASTOMOSIS}

The single-anastomosis requires less time to run than the two-layer anastomosis, is performed with less sutures, consequently, lower volume of foreign body is used. As should be performed preferably with a mucosal exclusion bowel wall does not suffer ischemic damage and is responsible for a rapid epithelialization of mucosa of the anastomosis site, sealing anastomosis internally within 24 to 48 hours. This fact that has been demonstrated in experimental studies. This detail makes the single-layer anastomosis theoretically to be safer than two-layer anastomosis. However, clinical studies have shown a similar risk of developing fistulas compared the two anastomosis techniques ${ }^{19-20}$.

When analyzing the postoperative outcome, the intestinal tract of patients who undergo a single-layer anastomosis has been more favorable than two-layer one. One factor that could be important is that single-layer anastomosis does not form a mucosa spur in the anastomosis site lumen, a fact that is observed after a two-layer anastomosis. For its simplicity, single-layer anastomosis can be 
introduced in any surgical training program with apparent low risk of technical difficulties and complications.

\section{QUALITIES OF A GOOD DIGESTIVE ANASTOMOSIS}

1- Being waterproof, preventing leakage

2 Regular and well coapted edges

3 No tension in the anastomosis zone

4 Not ischemic

5- The anastomotic edges should be well vascularized

6- Surgeons should ensure perfect hemostasis

7 Should not stenose the intestinal lumen

8 Should allow mucosal coverage

9- Consequently, it should allow the inversion of mucosa

\section{REFERENCES}

1- Oezcelik A, DeMeester SR. General anatomy of the esophagus. Thorac Surg Clin. 2011 May;21(2):289-97.

2- Pines G, Buyeviz V, Machlenkin S, Klein Y, Laor A, Kashtan H. The use of circular stapler for cervical esophagogastric anastomosis after esophagectomy: surgical technique and early postoperative outcome. Dis Esophagus. 2009;22(3):274-8.

3- Rutegård M, Lagergren P, Rouvelas I, Lagergren J. Intrathoracic anastomotic leakage and mortality after esophageal cancer resection: a population-based study. Ann Surg Oncol. 2012 Jan;19(1):99-103. doi: 10.1245/s10434-0111926-6.

4- $\mathrm{Hu} \mathrm{H}, \mathrm{Ye} \mathrm{T}$, Zhang $\mathrm{Y}$, Zhang J, Luketich JD, Chen $\mathrm{H}$. Modifications in retrosternal reconstruction after oesophagogastrectomy may reduce the incidence of anastomotic leakage. Eur J Cardiothorac Surg. 2012 Aug;42(2):359-63.

5- Kayani B, Okabayashi K, Ashrafian H, Harling L, Rao C, Darzi A, Kitagawa Y, Athanasiou T, Zacharakis E. Does obesity affect outcomes in patients undergoing esophagectomy for cancer? A meta-analysis. World J Surg. 2012 Aug;36(8):1785-95.

6- Alanezi K, Urschel JD. Mortality secondary to esophageal anastomotic leak. Ann Thorac Cardiovasc Surg. 2004 Apr;10(2):71-5. 
7- Soybel DI. Anatomy and physiology of the stomach. Surg Clin North Am. 2005 Oct;85(5):875-94.

8- Sah BK, Chen MM, Yan M, Zhu ZG. Gastric cancer surgery: Billroth I or Billroth II for distal gastrectomy? BMC Cancer. 2009 Dec 9;9:428.

9- Geboes K, Geboes KP, Maleux G. Vascular anatomy of the gastrointestinal tract. Best Pract Res Clin Gastroenterol. 2001 Feb;15(1):1-14.

10-Skandalakis JE, Skandalakis LJ, Colborn GL, Pemberton LB, Gray SW. The duodenum. Surgical anatomy. Am Surg. 1989 May;55(5):291-8.

11-Douard R, Chevallier JM, Delmas V, Cugnenc PH. Clinical interest of digestive arterial trunk anastomoses. Surg Radiol Anat. 2006 Jun;28(3):219-27.

12-Khashab MA, Pickhardt PJ, Kim DH, Rex DK. Colorectal anatomy in adults at computed tomography colonography: normal distribution and the effect of age, sex, and body mass index. Endoscopy. 2009 Aug;41(8):674-8.

13-Bourgouin S, Bège T, Lalonde N, Mancini J, Masson C, Chaumoitre K, Brunet C, Berdah SV. Three-dimensional determination of variability in colon anatomy: applications for numerical modeling of the intestine. J Surg Res. 2012;178(1):172-80.

14-Röttgen R, Fischbach F, Plotkin M, Herzog H, Freund T, Schröder RJ, Felix R. Colon dissection: a new three-dimensional reconstruction tool for computed tomography colonography. Acta Radiol. 2005 May;46(3):222-6.

15-Natale C, Ferrozzi L, Pellegrino C, Bruno L. Digestive anastomosis in general surgery. G Chir. 1998 Apr;19(4):175-83.

16-Slim K, Panis Y, Perniceni T, Escat J. Mechanical sutures in digestive surgery. Guidelines of the French Society of Digestive Surgery. J Chir. 2000 Feb;137(1):5-12.

17-Korolija D. The current evidence on stapled versus hand-sewn anastomoses in the digestive tract. Minim Invasive Ther Allied Technol. 2008;17(3):151-4.

18-Walther B, Johansson J, Johnsson F, Von Holstein CS, Zilling T. Cervical or thoracic anastomosis after esophageal resection and gastric tube reconstruction: a prospective randomized trial comparing sutured neck anastomosis with stapled intrathoracic anastomosis. Ann Surg. 2003 Dec;238(6):803-12.

19-Matheson NA, Irving AD. Single layer anastomosis in the gastrointestinal tract. Surg Gynecol Obstet. 1976 Oct;143(4):619-24.

20-Petitti T, Lippolis G, Ferrozzi L. [Manual colonic anastomosis with continuous single layer suture. Our experience]. G Chir. 2003 May;24(5):202-4. 